\title{
Where Do We Go from Here? Informing Academic Library Staffing through Reference Transaction Analysis
}

\section{Bradley Wade Bishop and Jennifer A. Bartlett}

\begin{abstract}
This study conducted a systematic sample of every 70th reference transaction from over a three-year period and analyzed 1,852 reference transactions asked at an academic library system's fifteen face-to-face (f2f) service points as well as via telephone, e-mail, and chat. Findings indicate two-thirds of the total questions asked were location-based questions about the library. Also, 80.2 percent of location-based questions and 77.2 percent of subject-based questions were asked f2f. Analysis of location-based reference questions informs effective deployment of librarians and staff at library service points as well as the development of mobile library apps.
\end{abstract}

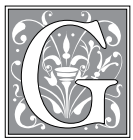

iven the ever-present challenges to staffing reference with declining budgets in the academic environment, coordinating the provision of information services requires using the right mix of librarians, library staff, and information technology. In 2010, 62.7 percent of undergraduate students owned Internetcapable handheld devices. ${ }^{1}$ With the rapid adoption of mobile technologies and advances in all digital resources, librarians and staff may now provide answers to user questions wherever those questions arise. The main benefit of "anyplace" information services is that the distance between users and librarians matters less for service provision. However, where the information gap occurs for the user and where the librarian is located to help answer questions still matters. ${ }^{2}$ When considering optimal staffing of academic libraries with limited resources, an analysis of the places where questions are asked provides valuable data to library managers facing tough staffing choices.

The problem this study addresses is that academic libraries must provide reference services to their students, faculty, staff, and community users in a timely, efficient manner with limited human resources. At the academic library system used in this study, only 56.7 percent of the transactions captured the patron type,

Bradley Wade Bishop is Assistant Professor, College of Communication and Information, University of Tennessee, wade.bishop@utk.edu. Jennifer A. Bartlett is Head of Reference Services, University of Kentucky Libraries; e-mail: jen.bartlett@uky.edu. The authors would like to acknowledge the University of Kentucky Libraries, University of Kentucky Regular Summer Faculty Research Fellowship award that funded this study, as well as the external raters that assisted with interrater reliability testing. (C) 2013 Bradley Wade Bishop and Jennifer A. Bartlett, Attribution-NonCommercial (http://creativecommons.org/licenses/by-nc/3.0/) CC BY-NC 
and therefore only limited analysis of who was asking could be done beyond where questions were asked. Of the questions with patron type data, 74.5 percent were students, 18 percent were community users, and 6.4 percent were faculty and staff. It is possible students comprised an even greater percentage of the users. Although who asks questions is an important aspect of staffing, this study focuses on where questions are being asked and assumes that the majority of walkup questions come from students.

Some have equated the rise in mobile devices with a decline in the need to staff a physical reference desk with professional librarians. ${ }^{3}$ Due to the speed of adoption of smart phones and mobile technologies, some academic libraries are producing mobile websites and applications (apps). Overall, the academic library community has been relatively slow in embracing them. ${ }^{4}$ Many academic libraries have a unique opportunity to mine the data collected at their public service desks to both create optimal staffing of $f 2 f$ service points and inform the creation of new venues to provide service. This paper will focus on content analysis findings related to staffing and discuss the implications of the method and findings for other academic libraries.

\section{Literature Review}

The University of Kentucky (UK) Libraries is in the process of developing mobile apps for users that will include a variety of library services, including catalog and database access, library location maps, library hours, and staff contact information. Literature on approaches to using this technology for the provision of library services is mounting with several years of research published in Handheld Librarian Online and m-Libraries Conferences, as well as a 2011 special double issue of The Reference Librarian. In 2010, 39 of 111 Association of Research Libraries (ARL) member universities had mobile websites, and 24 of those also had library-specific mobile websites. ${ }^{5}$ For those interested in a detailed process to develop a library app, there are several articles that detail the considerations for administration before embarking on building an app, including platform choice and how to determine what features students want. ${ }^{6}$

The potential services libraries can offer by using mobile technologies are vast. Of course, many libraries already offer catalog access and other basic library access information via an online app, including the Santa Clara County, Prince George, Topeka and Shawnee County, and Orange County public libraries in Florida. ${ }^{7}$ However, going one step further than the traditional OPAC, location-based mobile technologies can lead users directly to item locations in the stacks without staff intervention. Once the user looks up a book in a library's catalog, a path suggestion software system directs the user to the location of the book on the shelf using wireless access points and beacons. Such a system is already in use at the University of Oulu in Finland, and a similar study has recently been conducted at the University of Illinois. ${ }^{8}$

Many libraries are currently exploring the possibilities of QR (Quick Response) codes. QR codes are two-dimensional barcodes designed to be read by scanners on mobile devices; they can store more information than a traditional barcode. Common library apps for QR codes focus on linking the physical location with its digital equivalent. For example, scanning a QR code posted on the side of a shelving unit in the bound periodicals stacks might take the user to a library's full electronic holdings of journals in JSTOR or another database. Also, QR codes embedded in item records in an OPAC can lead the searcher to more information about the item.

As students' use of mobile technologies continues to increase, academic libraries are approaching the use of QR codes in a more consciously user-centric way. Analysis of reference transactions and librarian experience informs the efficient use of QR codes. At the University of Colorado at Boulder, the libraries began a study in fall 2010 using Microsoft Tag to plan a system 
of QR code prioritization and placement. Contacting librarians, technology assistance, and wayfinding became key areas of focus for the project. ${ }^{9}$

QR codes are also a component of a relatively new trend in libraries: augmented reality. Augmented (or virtual) reality may be loosely defined as "a computergenerated component that is added to the real environment." ${ }^{10}$ There is potential for apps to go beyond displaying flat information (for example, a brochure or audio tour) with augmented reality tools for smartphones like Layar (www.layar. com). In fact, North Carolina State Libraries built their own app called WolfWalk (www.lib.ncsu.edu/dli/projects/wolfwalk/), which overlays historical images from the library archives at more than 50 points around campus as well as providing the basic library flat information of other mobile library apps. Location-based content systems can include such varying formats as historical maps, photographs, oral histories, and more. For example, the British Library has launched an app highlighting key holdings in its vast collections, including manuscripts, musical scores, scientific and historical documents, and more. Content is supplemented with sound recordings and videos, and the app features updates on current exhibitions and events. ${ }^{11}$

Another possible application of mobile technology is "digital reunion," or the bringing together of disparate collections into a single unified information resource, regardless of ownership or geographic location. Location-based collections and resources can be curated into a unified resource that can be used anywhere, anytime. An interesting example is that of the Codex Sinaiticus, a fourth-century Christian Bible containing the oldest complete copy of the Christian New Testament. Pieces of the manuscript are distributed among the British Library, St. Catherine's Monastery in Sinai, the National Library of Russia, and Leipzig University. The existing pieces of the Codex have been digitized and reunited in a single online database (http://codexsinaiticus.org). Thus, researchers examining the actual manuscript in one location can view it in context with its original arrangement. ${ }^{12}$

With a wide variety of new mobile technologies and apps, the ideal of "ubiquitous" reference service is rapidly becoming the model of public services in the 21st-century library. It is now widely understood that more library users employ mobile devices for a variety of uses, both personal and professional. The challenge in academic libraries now is to adopt the right kind of technology at the right cost, with an informed staff offering stable services. Academic libraries must balance a "combination of mobile patrons, mobile content, and increasingly mobile librarians."13 Reference service is becoming increasingly decentralized - anytime, anywhere reference-which carries with it its own set of pressures, such as the expectation for 24/7 service and rapid (almost instant) response. ${ }^{14}$ However, even mobile users will continue to rely on $\mathrm{f} 2 \mathrm{f}$ interactions with librarians, and their optimal placement will continue to be important.

Increased demand for services can also create opportunities for collaboration. For instance, the "Library Outside the Library" team at Cornell University Libraries worked with students in a computer science class to develop an iPhone/ iPod Touch app with features including a catalog search, access to user accounts, contact and hours information, and an interactive map..$^{15}$ The wide variety of library mobile technologies may help answer many location-based questions and provide another venue for users to ask other questions (such as chat/text reference), but the same transaction analysis that could inform any mobile app development might also assist with staffing decisions related to both virtual and physical service points.

Analysis of reference transcripts allows libraries to determine the most frequently asked questions and also the service points at which questions are most frequently asked. ${ }^{16}$ In other studies, quantitative and qualitative analysis of data has helped to 
evaluate and improve library services, but few focus on location-based questions and the locations where those questions are asked. One study found 89 percent of reference transactions in an academic setting do not require librarian expertise to be answered, and any trained library staff could address most user concerns. ${ }^{17}$ Determining librarian expertise may not be reliably defined, but several locationbased question studies have found similar statistics that point to concerns on whether optimal staffing includes professional librarians at physical desks.

Location-based questions are inquiries that concern a georeferenceable site, and whether a question concerns a location or not provides a operationalizable definition for study..$^{18}$ The average percentage of location-based questions in seven studies conducted on virtual reference services was 47.3 percent. ${ }^{19}$ Location-based questions consist of two types: wayfinding questions (for instance, "Where is room 105 ?") and location-attribute questions (for example, "What are your hours?"). Past location-based question studies focused on virtual reference, since those researchers were concerned with the dynamics of remote reference staff answering questions beyond their location. The same typology is also useful to inform optimal library staffing by looking at where questions are asked.

The analysis of reference transactions answered at service points throughout UK Libraries provides not only content to inform staffing, but the development of a mobile library app as well. Proactively supplying answers to frequently asked wayfinding questions with a mobile app will allow librarians to reallocate their time to more in-depth reference queries and consultations. Still, users will ask $\mathrm{f} 2 \mathrm{f}$ questions, and a review of where questions are asked informs the locations where librarians' services may be needed most. At a time when a librarian may be anywhere to help users, does it matter where librarians are? The location of reference staff deserves further study, as technology removes the importance of distance, and staff remain a large expense for most libraries. This study is only one snapshot of findings, but it provides a model for future work in this area.

\section{Methodology}

The purpose of this study was to conduct content analysis of reference transactions to address these research questions:

1. What is the quantity of locationbased questions asked on campus?

2. What is the quantity of subjectbased questions asked on campus?

3. Where are these questions asked on campus?

Findings of this content analysis will assist the administration in making decisions to provide optimal staffing at academic library service points. Reference transactions also provide data on locationbased questions to inform a library mobile app, but the app will not answer all reference questions. Many questions asked at physical reference desks are not about any precise place, such as when a user needs to reset his or her password or locate articles for a research paper. With budget restrictions, academic libraries must face difficult decisions on how to provide the most optimal point-of-need reference services to their students, faculty, staff, and community users. Although staffing is a complicated issue and future studies would benefit from more comprehensive analysis of question typology and the users asking questions, those research questions are beyond the scope of this exploratory study and may be addressed by libraries that are collecting more detailed reference transaction data.

\section{Population and Sample}

UK Libraries has continuously collected reference transaction data at all service points since February 1, 2008. Librarians and library staff were trained to record each question and provide a summary of how each question was answered. Therefore, each question was treated as a separate transaction and no transactions included multiple questions. Many 
variables were collected with these data in Libstats, but for this analysis only the broad question type, reference mode, and location where the question was asked were used. Incidentally, these fields were the most consistently populated in the dataset. To review the transactions and provide representative results, the first three years of the data were sampled.

During the three-year period, UK Libraries conducted 129,572 reference transactions from February 1, 2008 to January 31, 2011 at its $15 \mathrm{f} 2 \mathrm{f}$ service points as well as via telephone, e-mail, and chat. Content analysis of a systematic sample of every 70 th question $(1,852)$ provided a snapshot of the quantities of locationbased questions, subject-based questions, and where they were asked on campus. This study's content analysis protocols were reviewed and approved by an Institutional Review Board.

\section{Data Collection and Content Analysis}

"Content analysis is a research technique for making replicable and valid inferences from texts (or other meaningful matter) to the context of their use." ${ }^{20}$ Content analysis of this study included several steps. Before analyzing question types and where the questions were asked, unusable transactions were removed. Unusable transcripts include question fields that were blank or fields with insufficient data to determine the questions asked (for instance, patrons). ${ }^{21}$ Although it was clear librarians and library staff left the question field blank in many instances, 72 percent of the systematic sample did retain enough to assess the question asked.

The question transactions with sufficient data allowed for coding whether a question was a location-based or a subject-based question, as well as to determine the location-based question subtypes. More detailed question typology was not explored here because that level of detail is beyond the scope of this study's focus on optimal staffing. Again, librarians and library staff were trained to record one transaction per question; consequently, no transactions included multiple questions.

The next step in content analysis included reliability testing for interrater and intrarater reliability. Reliability is when "scores from an instrument are stable and consistent." 22 To address interrater reliability, the researcher recruited and trained three external coders on an existing content analysis protocol and question typology codebook. The coders were library staff. In one hour, the external coders coded 30 randomly selected transcripts using the protocol. Coded material was compared across coders to ensure interrater reliability. An acceptable Krippendorff's $\alpha=.87$ percent (high level of relationship) was obtained. Krippendorff's alpha is a statistical measure that "generalizes across scales of measurement; can be used with any number of observers, with or without missing data; and it satisfies all of the important criteria for a good measure of reliability." 23

To address issues related to intrarater reliability, the researcher coded 30 randomly selected transcripts using the protocol from content analysis twice, allowing one month to pass between coding, to ensure reliability over time. An acceptable Cohen's kappa of .880 was obtained. Cohen's kappa measures the agreement between two raters who each classify $N$ items into $C$ mutually exclusive categories. The equation controls for the hypothetical probability of chance agreement, to calculate the probabilities of each observer randomly selecting each category. ${ }^{24}$ The reliability testing indicates this question typology operates reliably for this dataset.

With these promising reliability testing findings, the researcher completed content analysis of 1,852 transactions. The researcher conducted all content analysis for consistency using the protocol and question typology codebook. The usable transcripts included 1,333 that contained sufficient data to discern a question. These transcripts allowed the study to determine the quantities of location-based questions, subject-based questions, and the locations of where the different types of questions 
were asked. Table 1 provides an overview of the question typology with definitions.

\section{Findings}

Content analysis findings provided data to determine the quantities of locationbased and subject-based questions asked as well as where they were asked. Of the 1,333 usable transcripts with questions, 83.7 percent contained locationbased questions. Subject-based questions comprised the remaining 16.3 percent of transactions. Also, 80.2 percent of location-based questions and 77.2 percent of subject-based questions were asked $\mathrm{f} 2 \mathrm{f}$.

\section{Question Quantities}

The large majority $(83.7 \%)$ of questions concerned locations either within the libraries, on campus, or of some physical place. Location-based questions were either wayfinding (that is, directional) or attribute of a location. Wayfinding questions comprised only 11.5 percent of the total questions asked and 147 of 154 related to finding places inside the libraries, like study rooms, classes, bathrooms, and printing. The seven other wayfinding questions were about other buildings on campus or in the surrounding city. The attribute of location questions comprised 72.8 percent of the total question transac- tions, and most of those were about library service and resources. In fact, two thirds of the total question transactions that related to library services and resources included finding an item (19.6\%), printing (11.7\%), circulation (8.4\%), desk supplies (6.2\%), and computer problems (4.4\%). Other less frequently asked location-based questions included those about staff contact information, room access, hours, login, and parking. Due to the simple content of most location-based questions, library staff with minimal training or a mobile library app should be able to answer most of these frequently asked question types. Clearly, many users will still ask f2f questions to whoever is staffing service points.

Subject-based questions make up a much smaller portion of the total transactions compared to location-based questions. These questions are more difficult to categorize because of the variety and the fact they are not location-specific. Other existing question taxonomies may be used in future work to analyze the content of subject-based questions. ${ }^{25}$ These subjectbased questions may be more adequately answered by professional librarians and library staff regardless of their locations. In subject-based question instances, a user's location does not relate to the question at hand. Subject-based question types

\begin{tabular}{|l|l|}
\hline \multicolumn{2}{|c|}{$\begin{array}{c}\text { TABLE 1 } \\
\text { Study Variables and Definitions }\end{array}$} \\
\hline Variable & Definition \\
\hline $\begin{array}{l}\text { Question field blank or } \\
\text { indeterminable }\end{array}$ & $\begin{array}{l}\text { question field left empty or included insufficient data to dis- } \\
\text { cern a question (example: shelved books) }\end{array}$ \\
\hline Location-based question & question concerned the attributes of a georeferenceable site \\
\hline - Wayfinding & $\begin{array}{l}\text { question concerned where something is located or concerns } \\
\text { the physical relation of a location to another location (ex- } \\
\text { ample: where is White Hall?) }\end{array}$ \\
\hline - Attribute of a location & $\begin{array}{l}\text { question concerned the libraries' services and resources OR } \\
\text { question concerned other parts of the university beyond the } \\
\text { libraries OR } \\
\text { question concerned other places than the libraries or university }\end{array}$ \\
\hline Subject-based question & question did not concern the attributes of a georeferenceable site \\
\hline
\end{tabular}




\begin{tabular}{|l|c|c|}
\hline \multicolumn{3}{|c|}{ TABLE 2 } \\
Question Quantities by Reference Mode \\
\hline $\begin{array}{c}\text { Reference } \\
\text { Mode }\end{array}$ & $\begin{array}{c}\text { Number of } \\
\text { Location-Based } \\
\text { Questions }\end{array}$ & $\begin{array}{c}\text { Number of } \\
\text { Subject-Based } \\
\text { Questions }\end{array}$ \\
\hline Chat & $11(1.3 \%)$ & $8(0.6 \%)$ \\
\hline E-mail & $18(2.1 \%)$ & $8(0.6 \%)$ \\
\hline Phone & $137(16.3 \%)$ & $17(14.2 \%)$ \\
\hline f2f & $674(80.2 \%)$ & $85(71.4 \%)$ \\
\hline Total & $840(100 \%)$ & $119(100 \%) *$ \\
\hline *1 subject-based question was a research consult. \\
\hline
\end{tabular}

quality service from trained professionals regardless of where they are physically located.

\section{Question Locations}

To address the research question of where questions were asked, the fields of reference mode and location were used. Unfortunately, the reference mode field was missing on several transactions. Still, 72 percent of question transactions contained the reference mode field. Table 2 presents the results of questions asked by reference mode.

Despite other reference options, include citation help, using electronic resources and the OPAC, as well as any number of in-depth research questions. For these subject-based questions, users would still benefit most from trained reference staff, either librarians or library staff. Although the majority of questions asked were location-based, students, faculty, staff, and community users engaging in those 16.3 percent of transactions that have subject-based questions still require 79.1 percent of all questions were asked $\mathrm{f} 2 \mathrm{f}$. There are potentially a myriad of reasons for a lack of virtual reference use at UK, but one primary contributor may be an entire lack of marketing services. There is currently no one in the role of marketing at the libraries or any marketing efforts related to reference services because of budgets. Table 3 shows the results of questions asked at $\mathrm{f} 2 \mathrm{f}$ service points. The majority of $\mathrm{f} 2 \mathrm{f}$ questions were asked at the service points within

\begin{tabular}{|l|c|c|}
\hline \multicolumn{3}{|c|}{ TABLE 3 } \\
\hline Service Point & $\begin{array}{c}\text { Number of Location-Based } \\
\text { Questions Asked f2f (674) }\end{array}$ & $\begin{array}{c}\text { Number of Subject-Based } \\
\text { Questions Asked f2f (85) }\end{array}$ \\
\hline Young Library Periodicals & $177(26.4 \%)$ & $13(15.4 \%)$ \\
\hline Young Library Reference & $140(20.8 \%)$ & $31(36.5 \%)$ \\
\hline Fine Arts Library & $121(17.9 \%)$ & $8(9.4 \%)$ \\
\hline Law Library & $33(4.9 \%)$ & $13(15.4 \%)$ \\
\hline Education Library & $35(5.2 \%)$ & $6(7.0 \%)$ \\
\hline $\begin{array}{l}\text { Young Library Hub } \\
\text { (Information Commons) }\end{array}$ & $60(8.9 \%)$ & $2(2.3 \%)$ \\
\hline Science Library & $46(6.8 \%)$ & $2(2.3 \%)$ \\
\hline Young Library Circulation & $26(3.8 \%)$ & $8(2.3 \%)$ \\
\hline Other Service Points* & $36(5.3 \%)$ & $8.4 \%)$ \\
\hline $\begin{array}{l}\text { *Engineering Library, Chemistry Physics Library, Agricultural Information Center, Geology/Maps, } \\
\text { Library Link (closed), Design Library, Young Library Audio Visual Services, Kentucky Transporta- } \\
\text { tion Center, Lexmark Library }\end{array}$ & & \\
\hline
\end{tabular}


the university's large main library, Young Library. Young Library Reference receives the most subject-based questions, perhaps due to referral of subject-based questions from other service points.

To visualize the distribution of questions across campus, a map was produced. Although the majority of all questions were asked within Young Library, it is important to note that the default for phone questions is the Young Library. Just as other fields were incomplete, 71.4 percent of the reference transactions included the location. Still, map 1 depicts the quantities of total questions asked on campus to inform optimal staffing.

\section{Discussion}

The following discusses the implications of the method and findings for academic libraries. A review of the method includes limitations of this study and potential options for future research. This section also reviews the potential of how both staffing and library mobile apps may be informed by the study of location-based questions.

\section{Data Collection}

Data collection is a limitation of this study and data limitations may be common at many academic libraries. With busy service points with long lines, data collection of use statistics in a timely and complete way is a challenge. The tool used to collect library reference and directional statistics at UK Libraries was Libstats, an open source, web-based question tracking application that requires librarians and library staff to record transactions after they are completed. During hectic times, some questions are not recorded and some questions are inaccurately and incompletely recorded. As mentioned previously, some fields, like patron type, are only recorded a little over 50 percent of the time. In instances of incomplete data collection, the librarian or library staff person records a quick tally of either directional or reference without the other transaction details. Also, speaking to the issue of reliability is the repetitive nature of many simple questions, which may simply not be recorded at all. For example, staff state that the

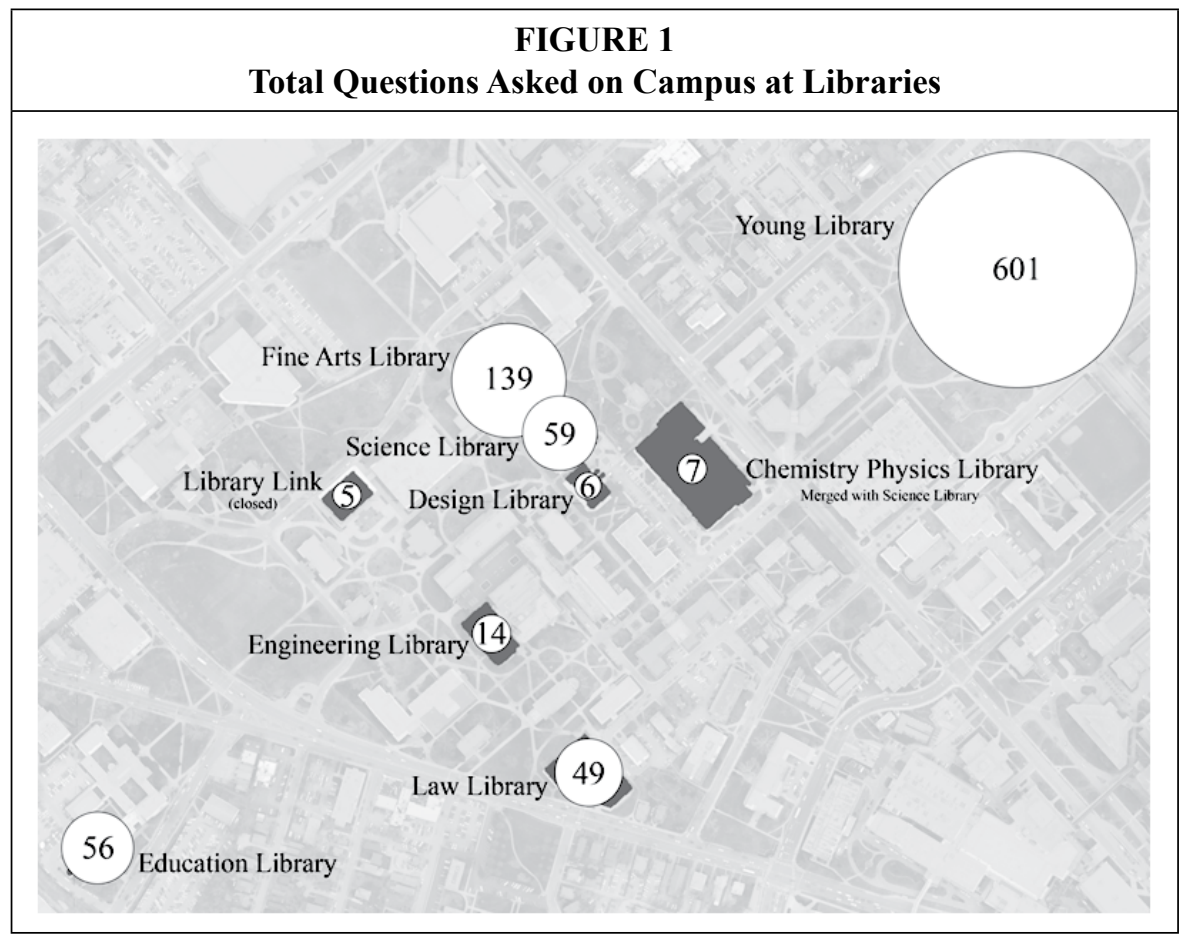


stapler and other supplies are constantly being borrowed, but only 9.4 percent of the total transactions recorded related to desk supplies. The real quantity of desk supply questions may be even higher, but data collection is incomplete.

Two approaches to overcome data collection issues are to simplify the recording process and increase training. Currently, when users ask questions, the only record of each question is a subjective summary by public services staff. Although the staff is trained to describe the content of each question asked, a dropdown menu with options from this study's question typology built into reference software may speed up the data collection process. In turn, more complete and detailed data would enrich analysis of reference work beyond simple counts. Increased and targeted training of front-line public services staff on data collection should result in more complete transaction records. Staff realize the value of justifying their positions through data collection, but the process should be less cumbersome. In some instances, question types will not fit neatly into some of the FAQ identified in this exploratory study, but Libstats and other programs allow staff to input qualitative data for those instances. By implementing some of these suggestions, future studies will have better and more comprehensive data collection, which should lead to improved services.

Also, administration could tailor training based on the types of questions asked in specific places. Although some interpersonal communication and other needed skills are obvious without analysis, such as staff in the computer lab having basic training in computer troubleshooting, training at other service points may need revisiting based on service point-specific findings. For example, staff at a reference desk in a research room are likely to need the information literacy skills that come with specialized professional training.

Starting in January 2012, UK Libraries will implement the LibAnswers platform, from Springshare LLC. LibAnswers is a
24/7 "ask-a-librarian" platform allowing not only the recording of $\mathrm{f} 2 \mathrm{f}$, telephone, e-mail, text message, and chat reference transactions, but also providing an instantly accessible knowledge base of FAQ, both location-based and subject-based, and answers. The current study's findings and replication of this method with new data gathered through LibAnswers will help inform its knowledge base function.

A strength of this study was the reliable protocol used for content analysis. Future studies analyzing reference transactions should include reliability testing to ensure that data analysis is done reliably. Findings based upon analysis without reliability testing may be unreliable. To improve future research, some testing of protocols should be conducted prior to review of transactions. Creating more reliable data is crucial for findings that impact the allocation of human resources.

\section{Implications for Staffing}

This study's method determines both the quantity of questions and the location where they were asked. Without testing the assumption that location-based questions are easier to answer, one may assume that location-based questions are addressed with minimal training. ${ }^{26}$ The quantities of these questions and where all questions are asked have implications for staffing in a number of academic libraries.

An issue most academic libraries deal with is balancing user questions with existing staff numbers. Many academic campuses offer library services at multiple service points within libraries and across campus. With limited resources and the high cost of staff, managers must decide where and when to staff service points. Which service points are critical to maintain library service quality? Who should staff each one? Each institution may have its own approach on how to address these questions. For UK Libraries, this content analysis informed management of the quantities and types of questions asked at different places around campus. Other information environments and academic 
libraries may find different results with the same method. The following discusses UK Libraries' findings specifically and encourages readers to consider how these issues translate to their institutions without generalizing quantities beyond this study's sample.

The location-based question types most asked in this study were basic and somewhat repetitive in nature. Staff with minimal training may answer many location-based questions. However, users may start with a simple question that leads to more complicated queries about library resources and services. Users may become familiar with service points, both physical and virtual, as comfortable places to find information and ask subjectbased questions.

Training helps staff clarify a user's question and reduces the likelihood of providing inappropriate information in response to the user's original, oftenambiguous query. ${ }^{27}$ Mobile applications have not yet progressed to the complexity of conducting such a reference interview. Therefore, for most transactions, users will require access to librarians wherever they are located. In f2f, users with simple location-based questions about printing may harbor questions that are more complicated. If the person staffing the desk does not know how to help or who in the library system may help, the user's information gap remains and users may be referred to subject-area specialists.

\section{The Potential of Data-Driven Mobile Library Applications}

A secondary implication of this study is the potential for data analysis to inform mobile library apps. Academic libraries will always require librarians, albeit at times hidden virtually behind technology, to assist users and maintain successful library service. Still, an app may serve some users in answering questions when and where he or she has them. Locationbased questions about finding a physical item, printing, circulation policies, desk supplies, and computer issues comprised
83.7 percent of the total transactions. Since these questions are location-specific, a mobile library app could be developed to address these questions.

Of course, without study there is no way of predicting whether a mobile app would reduce f2f questions. Students, faculty, staff, and the community will still likely ask questions of real people, but only if they are still staffing service points. With reduced funding, there is hope that an app can fill the gap in service left behind at vacated service points.

For example, if a student needs to find a book at a particular location, the app would detect the student's location on campus or within a particular building and provide directions from that location to the book. Therefore, staff may not have to assist that user and leave their service point unattended, and users can get help from an app when service points are unstaffed. Similarly, a user would be directed to the nearest available computer by functionality of a library app without asking a person. In short, many answers provided by a mobile library app will be location based, and some users may rely on such an app. Without future study, this is entirely speculation.

Although most libraries will develop mobile library apps without content analysis of reference transactions, the data produced from this study's approach helps highlight frequencies of questions to inform the FAQ that any app should address. For example, every academic library needs to help users in locating physical items and reserving rooms; however, some categories may go unnoticed and remain absent from mobile library apps without analysis. These might include circulation policy questions, computer availability, and how and where to print.

A mobile library app could address finding a particular item in the stacks or locating the nearest color printer. Printing, which represented nearly 12 percent of the total transactions at UK Libraries, is usually a straightforward procedure requiring basic sequential instructions. Whether an app or minor assistance from 
library staff, the process is simple. Future work may explore which combination of apps and staff is most cost-effective. However, this is beyond the scope of this study since the library app is new and adoption is still small among students.

Again, a mobile library app will not be able to answer complicated research questions without considerable programming beyond today's technology. Still, the majority of the questions in the present study did not require research assistance, and an app could potentially answer some questions. Most f2f questions, and especially the 16.3 percent of subject-based questions, will always benefit from the high-quality service of trained professionals. With the implementation of a mobile library app and virtual librarians, some users may ask fewer questions at physical library service points, but this assumption requires future study.

\section{Conclusion}

Despite some data limitations, content analysis of location-based questions may inform a library's level of staffing, its staff's locations of deployment, and the training staff's needs for efficient performance at different service points. This study offers a practical approach to strategically placing staff at service points based upon the quantity of questions asked at those locations. Based on the transactions collected by librarians and library staff, managers may attempt to predict the types and quantities of questions asked at various locations. Perhaps the combination of carefully placed staff and a helpful mobile library app could provide a tiered service across campus.

Staff should remain strategically placed to facilitate better use of their experience and training based on the types of questions asked at each service point. For subjectbased questions, a library app would refer users to staff, whether physically on site or remotely via telephone, chat, text messaging, or e-mail. Of the 176 academic libraries in a recent staffing study, approximately 65 percent (113) saw declines in FTE staff between 2000 and $2008 .{ }^{28}$ For users of these library facilities, multiple information desks could be staffed with personnel having a basic level of training concerning the facility and its services, or at the very least a QR code for a mobile library app. Future research on mobile library apps is necessary; however, their use should be able to improve library services and resources. These services would always need the functionality to quickly refer users to more highly trained library staff for subject-based questions that require more research skills. Virtual reference allows librarians to be everywhere on campus at once; however, this study indicates 79.1 percent of the total transactions occurred in $\mathrm{f} 2 \mathrm{f}$.

Despite the finding that two-thirds of the total questions asked concerned library locations and their attributes, all of which staff with minimal training may easily answer, 16.3 percent of transactions were subject-based questions and require professional help. Therefore, in this library system, professionals will be allocated to the places that have been asked the most subject-based questions, and other service points will refer users whether physically or virtually to those locations. With this approach, UK Libraries can optimally serve students, staff, faculty, and the community, while limiting the costs associated with staffing. For many academic libraries, a tiered approach already exists, but researchers at those institutions may want to validate their staffing models with similar content analysis to this study. The physical allocation of staff as an academic library's most expensive and valuable resource should warrant some evaluation at any institution.

\section{Notes}

1. Shannon Smith and Judith B. Caruso, The ECAR Study of Undergraduate Students and Information Technology, 2010: Key Findings (Boulder, Colo.: EDUCAUSE Center for Applied Research, 2010). 
2. Bradley Wade Bishop, "Location-Based Questions and Local Knowledge," Journal of the American Society for Information Science and Technology 62, no. 8 (2011): 1594-1603.

3. Sarah Barbara Watstein and Steven J. Bell, "Is There a Future for the Reference Desk? A Point-Counterpoint Discussion," Reference Librarian 49, no. 1 (2008): 1-20.

4. Gregory Little, "Keeping Moving: Smart Phone and Mobile Technologies in the Academic Library," Journal of Academic Librarianship 37, no. 3 (2011): 267-69.

5. Alan W. Aldrich, "Universities and Libraries Move to the Mobile Web," EDUCAUSE Quarterly Magazine 33, no. 2 (2010).

6. Chad Haefele, "One Block at a Time: Building a Mobile Site Step by Step," Reference Librarian 52, no. 1-2 (2010): 117-27; Jamie Seeholzer and Joseph A. Salem, "Library on the Go: A Focus Group Study of the Mobile Web and the Academic Library," College E Research Libraries 72, no. 1 (2009): 9-20.

7. Ellen Forsyth, "Ar U Feeling Appy? Augmented Reality, Apps and Mobile Access to Local Studies Information," Aplis 24, no. 3 (2011): 125-32.

8. Jim Hahn et al., "Methods for Applied Mobile Digital Library Research: A Framework for Extensible Wayfinding Systems," Reference Librarian 52, no. 1/2 (2011): 106-16.

9. Alison Hicks and Caroline Sinkinson, "Situated Questions and Answers: Responding to Library Users with QR Codes," Reference E User Services Quarterly 51, no. 1 (2011): 60-69.

10. Harry E. Pence, "Smartphones, Smart Objects, and Augmented Reality," Reference Librarian 52 (2011): 137.

11. British Library Treasures Online (N.D.), available online at http://apps.toura.com/britishlibrary/treasures [accessed 12 December 2011].

12. Forsyth, "Ar U Feeling Appy?"

13. Fred D. Barnhart and Jeannette E. Pierce, "Becoming Mobile: Reference in the Ubiquitous Library," Journal of Library Administration 51, no. 3 (2011): 280.

14. Thomas A. Peters, "Left to Their Own Devices: The Future of Reference Services on Personal, Portable Information, Communication, and Entertainment Devices," Reference Librarian 52, no. 1/2 (2011): 88-97.

15. Matthew Connolly, Tony Cosgrave, and Baseema B. Krkoska, “Mobilizing the Library's Web Presence and Services: A Student-Library Collaboration to Create the Library's Mobile Site and Iphone Application," Reference Librarian 52, no. 1/2 (2011): 27-35.

16. Jeffrey Pomerantz, "AConceptual Framework and Open Research Questions for Chat-Based Reference Service," Journal of the American Society for Information Science \& Technology 56, no. 12 (2005): $1288-302$.

17. Susan M. Ryan, "Reference Transactions Analysis: The Cost-Effectiveness of Staffing a Traditional Academic Reference Desk," Journal of Academic Librarianship 34, no. 5 (2008): 389-99.

18. Bishop, "Location-Based Questions and Local Knowledge."

19. Bishop, "Location-Based Questions and Local Knowledge"; Teresa U. Berry, Margaret M. Casado, and Lana S. Dixon, "The Local Nature of Digital Reference," Southeastern Librarian 51, no. 3 (2003): 8; Bradley Wade Bishop and Matt Torrence, "Virtual Reference Services: Consortium Versus Stand-Alone," College E Undergraduate Libraries 13, no. 4 (2006): 117-27; Loree Hyde and Caleb Tucker-Raymond, "Benchmarking Librarian Performance in Chat Reference," Reference Librarian 46, no. 95/96 (2006): 5-19; Nahyun Kwon, "Public Library Patrons' Use of Collaborative Chat Reference Service: The Effectiveness of Question Answering by Question Type," Library $\mathcal{E}$ Information Science Research 29, no. 1 (2007): 70-91; Lorri Mon et al., "The Geography of Virtual Questioning," Library Quarterly 79, no. 4 (2009): 393-420; JoAnn Sears, "Chat Reference Service: An Analysis of One Semester's Data," Issues in Science and Technology Librarianship (Fall 2001), available online at www.istl.org/01-fall/article2.html [accessed 12 December 2011].

20. Klaus Krippendorff, Content Analysis: An Introduction to Its Methodology (Thousand Oaks, Calif.: Sage, 2004), 18.

21. Jeffrey Pomerantz, Lili Luo, and Charles R. McClure, "Peer Review of Chat Reference Transcripts: Approaches and Strategies," Library E Information Science Research 28, no. 1 (2006): 24-48.

22. John W. Creswell, Educational Research: Planning, Conducting, and Evaluating Quantitative and Qualitative Research (Upper Saddle River, N.J.: Pearson Education, 2005), 162.

23. Andrew F. Hayes and Klaus Krippendorff, "Answering the Call for a Standard Reliability Measure for Coding Data," Communication Methods and Measures 1, no. 1 (2007): 78.

24. Cohen's kappa, Wikipedia, the free encyclopedia, available online at http://en.wikipedia.org/w/ index.php?title=Cohen\%27s_kappa\&oldid=333960161 [accessed 12 December 2011].

25. Julie Arnold and Neal K. Kaske, "Evaluating the Quality of a Chat Service," portal: Libraries and the Academy 5, no. 2 (2005): 177-93.

30. Walter A. Katz, Introduction to Reference Work (New York: McGraw Hill, 2002).

26. Robert S. Taylor, "Question-Negotiation and Information Seeking in Libraries," College and Research Libraries 29 (1968): 178-94.

27. Ibid.

28. Christopher Stewart, "Half Empty or Half Full? Staffing Trends in Academic Libraries at U.S. Research Universities, 2000-2008," Journal of Academic Librarianship 36, no. 5 (2010): 394-400. 